\title{
Estimativa Teórica do Potencial de Geração de Energia Elétrica a partir de Cana-De-Açúcar, Capim Elefante e Coco da Bahia no Brasil
}

\author{
Theoretical Estimate of the Potential of Electricity Generation from Sugarcane, \\ Elephant Grass and Coconut in Brazil
}

Diogo Alex Santos de Andrade'; Luís Oscar Silva Martins²

\begin{abstract}
${ }^{1}$ Universidade federal do Recôncavo da Bahia - UFRB, Campus Cruz das Almas - Bahia, Brasil, 44380-000, diogoandrade.engcivil@gmail.com; https://orcid.org/0000-0002-9494-2300

${ }^{2}$ Universidade federal do Recôncavo da Bahia - UFRB, Campus Feira de Santana - Bahia, Brasil, 44042-280, luisoscar@ufrb.edu.br; https://orcid.org/0000-0002-0040-7762
\end{abstract}

\begin{abstract}
Resumo
Os atuais problemas de fornecimento de energia associados à conscientização sobre as mudanças climáticas têm motivado a academia a pesquisar fontes renováveis de combustíveis e a dedicar maiores esforços ao estudo de sua eficiência energética e impactos socioambientais. Dentre as fontes energéticas de origem renovável, a biomassa se apresenta de forma promissora. Engloba, entre outros, vegetação, cultivos energéticos, bem como biossólidos, resíduos animais, florestais e agrícolas, a fração orgânica de resíduos urbanos e certos tipos de resíduos industriais. Nesse sentido, este estudo apresenta uma análise preliminar do potencial de geração de energia elétrica a partir de biomassa vegetal provenientes de diferentes regiões brasileiras. Foram analisados os resíduos derivados da cana-de-açúcar (Saccharum Officinarum), coco-da-baía (Cocos Nucifera) e a gramínea capim elefante (Pennisetum purpureum Schum). A partir dos valores de suas safras, referentes à 2017/2018, juntamente com os valores dos poderes caloríficos inferiores pesquisados junto à literatura pertinente, foram construídos mapas temáticos que demonstraram o potencial teórico de geração de eletricidade das culturas. Os resultados demonstraram que, para a cana, cujo estágio de desenvolvimento e utilização já estão consolidados, ainda existe espaço para exploração. O capim elefante apresentou alto potencial e capacidade de crescimento, enquanto que o coco-da-baía pode ser uma alternativa energética, especialmente para o Nordeste, apesar dos problemas relacionados a umidade deste último.
\end{abstract}

Palavras chave: biomassa, potencial energético, energia elétrica, fontes renováveis. 


\begin{abstract}
The current energy supply problems associated with climate change awareness have motivated academia to research renewable sources of fuel and to devote greater efforts to the study of its energy efficiency and socio-environmental impacts. Among the energy sources of renewable origin, biomass presents a promising. It encompasses, among others, vegetation, energy crops, as well as biosolids, animal, forest and agricultural waste, the organic fraction of municipal waste, and certain types of industrial waste. In this sense, this study presents a preliminary analysis of the potential of electricity generation from vegetable biomass from different Brazilian regions. The residues derived from sugar cane (Saccharum Officinarum), coconut bay (Cocos Nucifera), and elephant grass (Pennisetum purpureum Schum) were analyzed. Based on the values of their harvests, referring to 2017/2018, together with the values of their lower calorific powers researched in the pertinent literature, thematic maps were constructed, which demonstrated the theoretical potential of electricity generation of crops. The results showed that, for sugarcane, whose stage of development and use is already consolidated, there is still room for exploration. Elephant grass presented high potential and growth capacity, while coconut bay can be an energy alternative, especially for the Northeast, despite the problems related to humidity of the latter.
\end{abstract}

Keywords: biomass, energy potential, electricity, renewable sources.

\title{
1. Introdução
}

O Brasil passa por uma das suas maiores crises hídricas, principalmente, devido à falta de chuva nos principais reservatórios que alimentam as Usinas Hidrelétricas, situação que já perdura anos. Como consequência direta desse fato, o racionamento de água e políticas públicas de economia de eletricidade, como as bandeiras tarifárias, são problemas reais, deflagrados, e diretamente relacionados com o fato de que cerca de 65\% (Balanço Energético Nacional - BEN, 2018) da energia elétrica consumida no país é oriunda das usinas hidrelétricas e por conta disso, é comum a necessidade de recorrer a energia gerada pelas termoelétricas, impactando nas despesas do consumidor.

O país, por sua vez, não dispõe da quantidade significativa de carvão mineral e gás natural, que são fontes primárias para geração de energia termoelétrica, para atender à necessidade nacional, tendo que recorrer as importações. Outro fator que agrava a crise hídrica é a falta de administração das águas fornecidas pelas concessionárias do país, sendo que cerca de $40 \%$ da água tratada escoa ou se perde por furos nas instalações precárias ou roubos por parte da população. Portanto, sendo o Brasil um país predominantemente agropecuário e com vasta 
extensão territorial e litorânea, o mesmo apresenta um cenário ideal para implantação de uma tecnologia limpa e sustentável ao meio ambiente, que no caso estudado, é o uso da biomassa (Carmo \& Hasan, 2015, Barum, 2009).

A biomassa é considerada uma fonte promissora de energia na qual pode ser obtida nos três estados da matéria: gasoso (biogás), líquido (etanol, metanol e biodiesel) e sólido (resíduos agropecuários, industriais, vegetais não lenhosos ou lenhosos). As características e disponibilidade regional da biomassa são definidas como um conjunto de indicadores para sustentabilidade, em especial com foco no meio ambiente e aplicação de critérios socioeconômicos. A definição de biomassa, considerando-se o aspecto energético, é todo recurso renovável cuja origem é matéria orgânica, seja ela animal ou vegetal, que pode ser processado tecnologicamente para produção de energia mecânica, elétrica ou térmica (AGÊNCIA NACIONAL DE ENERGIA ELÉTRICA - ANEEL, 2008).

A geração de energia através da utilização de biomassa possibilita uma variedade de aspectos que induzem a análises interessantes. Este tipo de geração é geralmente feito em pequena escala (usinas de até $100 \mathrm{MW}$ ), possibilitando uma geração localizada, descentralizando todo o processo de geração, permitindo que uma comunidade mais carente possa gerar sua energia obtendo um conjunto de vantagens. Além disso, o uso da biomassa tem gerado novas oportunidades de trabalho em países onde já foram implementadas as políticas federais, estaduais e regionais para o setor (Barum, 2009).

A participação da biomassa nas regiões brasileiras para geração de energia elétrica está muito restrita ao bagaço de cana (cerca de 40\%, informação retirada do BEM, 2018), subproduto da indústria da cana-de-açúcar, e à cogeração no setor de papel e celulose, com o resíduo licor negro. Essa participação, entretanto, poderia ser maior com a inserção de novas opções de matérias sustentáveis com potencial energético, como por exemplo os óleos vegetais, da madeira reflorestada e dos resíduos agrícolas, do capim elefante e coco-da-baía, uma vez que, a atual regulamentação do setor elétrico permite a livre iniciativa e a concorrência tanto na geração quanto na comercialização de energia (Dias et al., 2017).

Nesta pesquisa foi analisado o potencial de geração de energia elétrica a partir de biomassa, com ênfase em três culturas diferentes, a da cana-de-açúcar, por ser um produto de plantio 
bastante difundido no Brasil, a de coco-da-baía e o capim elefante. Dessa forma, o objetivo geral foi mapear e analisar o potencial de geração de energia elétrica, e o potencial excedente, quando for o caso, a partir das culturas bioenergéticas supracitadas. Para tanto, foram identificadas e caracterizadas as biomassas de interesse do, bem como, realizado a mensuração do potencial de geração de eletricidade, a partir dessas rotas de conversão, tendo os resultados sido expostos e avaliados a partir de mapas temáticos.

\section{Principais Fontes Disponíveis para Geração de Energia Elétrica no Brasil}

A principal fonte de energia do Brasil são as hidrelétricas, devido a abundância de bacias hidrográficas, atende a maioria dos municípios, cerca de $92 \%$, porém sofre com a escassez de chuvas, os baixos níveis dos reservatórios, além de afetar o ecossistema (Tolmasquim, 2016).

De acordo com o Ministério de Minas e Energia (MME, 2018), as fontes renováveis seguiram com ampla participação na matriz energética brasileira. Em junho representaram cerca de $81,9 \%$ da capacidade instalada de geração de energia elétrica e $87,8 \%$ da produção total verificada no País. Em relação ao ano anterior no mesmo período, junho, as fontes cresceram cerca de 7.401 MW, sendo 3.450 MW de geração hidráulica, 2.219 MW de eólica, 1.365 MW de fonte solar e a biomassa com $524 \mathrm{MW}$.

Ainda, seguindo o MME, 2018, no período de um ano a geração por intermédio de hidrelétrica cresceu 3,5\%, atingindo um total de capacidade instalada de 102.228 MW. A fonte eólica cresceu 20,7\% e a biomassa obteve uma elevação de 3,7\%, somando ao todo 14.657 MW. A capacidade instalada do total das usinas que utilizam petróleo e carvão foi reduzida em 2,8\% e $0,4 \%$ respectivamente. Em comparação com as fontes térmicas, a biomassa, matéria orgânica não-fóssil de origem animal ou vegetal, alcançou 9,1\% de participação na capacidade instalada de geração, chegando ao crescimento dos 3,7\%. A fonte segue em constante crescimento e já se contabilizam cerca de 561 usinas, dos mais diferentes tipos de classe de combustíveis de biomassa, alguns dos mais comuns são: carvão vegetal, resíduos de madeira, bagaço de canade-açúcar, casca de arroz, licor negro, biogás, capim elefante e óleo de palmiste. A Fig. 1 demonstra a matriz de capacidade instalada. 


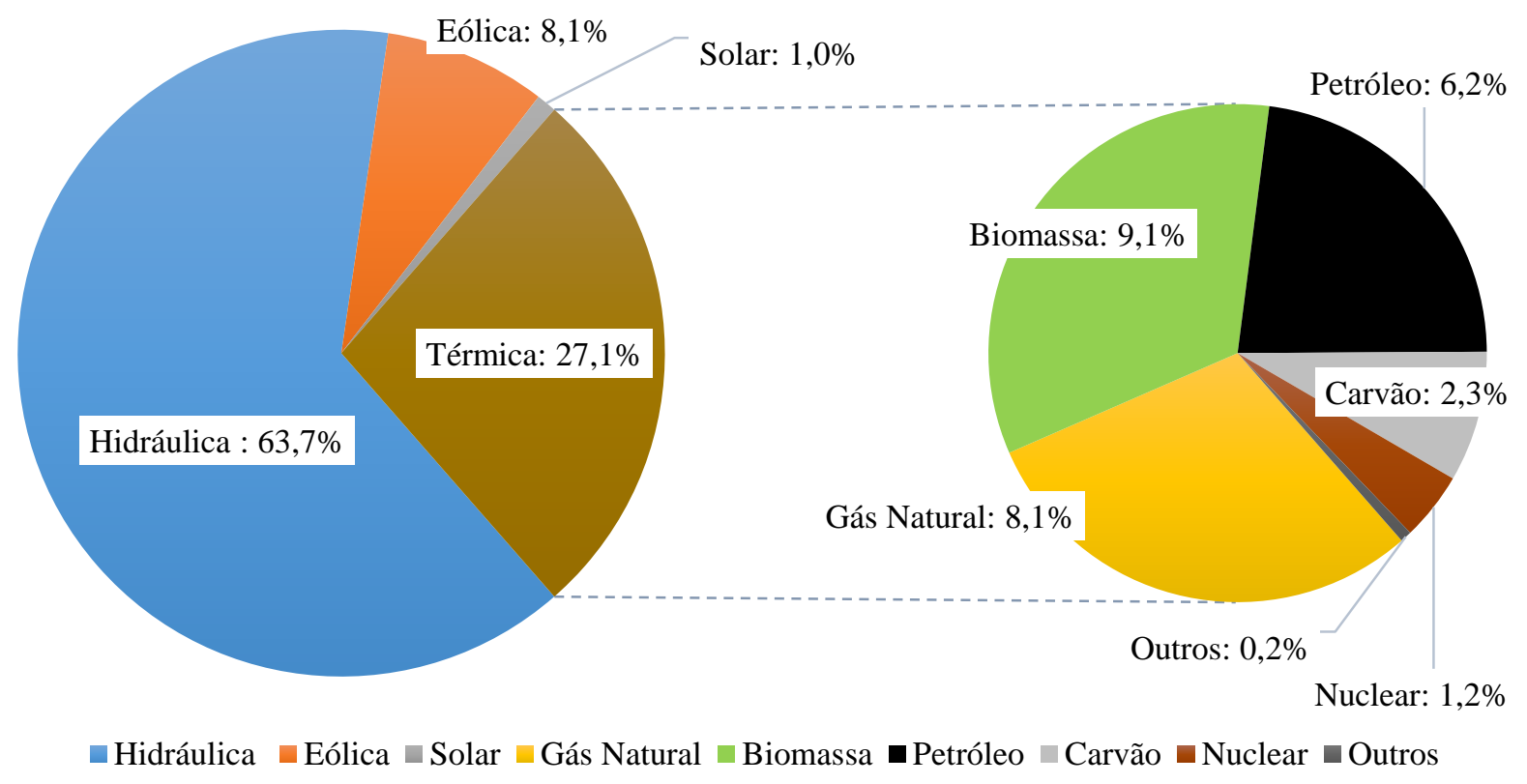

Figura 1. Matriz da capacidade instalada de geração de energia elétrica do Brasil sem importação contratada.

\subsection{Biomassa}

A Biomassa é a massa total de organismos vivos numa área, constituindo uma reserva de energia importante, pelo fato de ser formada basicamente por hidratos de carbono. Do ponto de vista energético, com fim voltado ao setor elétrico, a biomassa é um recurso renovável proveniente dos mais diversos tipos de matéria orgânica existente hoje, podem ser de origem vegetal ou animal. Uma das principais vantagens da biomassa que apesar de possuir uma eficiência menor do que as outras fontes, seu aproveitamento pode ser feito diretamente por meio de combustão em fornos e caldeiras.

Segundo Santos \& Torres (2017) a biomassa é uma alternativa renovável viável para diversificar as matrizes energéticas dos países, em substituição dos combustíveis fósseis (petróleo e carvão), na produção de bioeletricidade via usinas termelétricas (UTE). A biomassa, como já foi dito, é uma fonte renovável muito promissora no Brasil, a mais tradicionais, a exemplo de lenha e cana, já são bastante utilizadas, enquanto as biomassas mais modernas, voltadas para fins energéticos têm um amplo potencial de implantação, é o caso de culturas como o capim elefante e o coco-da-baía. 
Com base em pesquisas da Agência Internacional de Energia (IEA, 2012), o Brasil representa $80 \%$ da geração de energia das Américas Central e Sul. Tolmasquim (2015), afirma que em 2014 a bioeletricidade gerada pela lenha, bagaço de cana e lixívia totalizou cerca de 44,7 TWh de energia, uma equivalência de mais ou menos $8 \%$ da geração elétrica total do país, vale ressaltar que entre os três materiais utilizados, o bagaço de cana gerou 32,3 TWh.

As regiões do Sudeste e Centro-Oeste, atualmente, abrigam a maioria das UTE movidas a biomassa, as matérias orgânicas que alimentam as usinas são provenientes de resíduos florestais, agrícolas (cana-de-açúcar, arroz), cultivos exclusivamente com fins energéticos (capim elefante, eucalipto) e resíduos sólidos urbanos (RSU). Portanto, o Brasil possui diversos tipos de biomassa para serem utilizadas na geração de energia e, portanto, diversificar a matriz elétrica nacional, reduzindo a dependência de importação energética frente a outros países.

A biomassa quando utilizada para fins energéticos, é classificada em três classes: florestal, agrícola e rejeitos urbanos. No presente trabalho será dado ênfase a classe agrícola, onde estão incluídas as culturas agroenergéticas, resíduos e subprodutos dessas atividades agrícolas, agroindustriais e produção animal. As diversas fontes oleaginosas são pesquisadas com veemência como fontes de energia renovável, pois possibilita uma geração de energia descentralizada, além de dar um forte apoio à agricultura familiar, quando se utilizam oleaginosas específicas para o seu uso final.

\subsubsection{Cultura da Cana-de-açúcar}

A cana-de-açúcar é uma gramínea com uma haste fibrosa espessa, com tamanho final de aproximadamente 6 metros de altura. A espécie mais comum é Saccharum officinarum. A cana é constituída por raízes, talho, folhas e flores. O recurso de maior potencial para geração de energia elétrica no país é o seu bagaço. A alta produtividade alavancada pela lavoura e acrescida de ganhos nos processos de transformação da biomassa sucroalcooleira, tem disponibilizado enorme quantidade de matéria orgânica nas usinas. Além disso, a estiagem das principais bacias hidrografias do Brasil coincide com período de colheita da cana-de-açúcar, tornando uma opção ainda mais vantajosa (Cardoso, 2011; 2012).

O Brasil é o maior produtor e exportador de açúcar do mundo, pioneiramente passou a 
produzir combustível liquido renovável a partir da sacarose, o etanol, que atualmente figura com uma certa importância na matriz energética brasileira. A cana por ser bastante cultivada no país oferece oportunidade para o Brasil aumentar ainda mais o poderio de competição em matéria de energia renovável de biomassa, não só com benefícios a sociedade brasileira, mas também com um alto valor energético (Santos et al., 2012).

A maior produtividade ficou a cargo da região do Nordeste, porém a média brasileira foi semelhante à safra passada, de 72,543 kg/ha, o que acabou não impactando na produção. Ainda de acordo o boletim da CONAB, a produção etanol manteve-se estável, com 27,76 bilhões de litros e redução de $0,2 \%$. Já o açúcar caiu para 37,78 milhões de t, com retração de 2,1\% em relação à safra anterior, isto devido à menor quantidade de cana disponível e o direcionamento para a produção de etanol, em virtude dos preços no mercado internacional que caíram.

Com base no Banco de Informações de Geração (BIG, 2019) da ANEEL, o bagaço de canade-açúcar possui uma capacidade instalada de $11.352 .247 \mathrm{~kW}$, cerca de 6,63\% da matriz energética do país. No total de 563 usinas que utilizam a biomassa no Brasil como fonte de energia e das 424 usinas agroindustriais, 407 produzem energia elétrica através do bagaço de cana-de-de-açúcar. Em construção são cerca de 4 para uma potência outorgada, prevista, de 178.250 kW e empreendimentos não iniciados há 18 novas usinas em fase de planejamento, nas quais 8 são do bagaço da cana.

\subsubsection{Cultura do Capim Elefante}

O capim elefante é uma gramínea perene com altura entre três e cinco metros, original do território africano, foi trazida para servir de pastagem e é utilizada principalmente na criação de gado de corte e leiteiro. As características principais são o rápido crescimento, a tolerância com solos pobres de nutrientes e a geração de biomassa por área é alta. Seu poder calorifico inferior é, em média, $3.441 \mathrm{Kcal} / \mathrm{kg}$, com 25\% de água. A colheita do capim elefante pode ser feita seis meses após o seu plantio e permite de duas a quatro colheitas por ano, permitindo um fornecimento de biomassa durante todo o ano. Como uma vantagem, a cultura do capim elefante é altamente eficiente na fixação do $\mathrm{CO} 2$ atmosférico durante o processo de fotossíntese para a produção da biomassa vegetal, gerando uma contribuição do efeito estufa. Já uma desvantagem 
é o seu transporte, pois se não passar pelo processo de secagem, não poderá ser amontoado para evitar o apodrecimento, além disso, após o processo de secagem, o volume do capim elefante é grande (Cardoso, 2012).

No Brasil existem muitos tipos de capim chamados de capim elefante e somente na última década que começou a chamar a atenção da sociedade para o seu valor energético. A Embrapa por exemplo tem intensificado as pesquisas na área. De acordo com Mazarella (2007), em média, o capim elefante gera em torno de 40 a 45 toneladas de biomassa seca. O capim elefante tem uma larga vantagem em relação a produtividade em comparação com outras culturas, por exemplo, uma mesma área plantada de eucalipto, outra fonte de biomassa, renderia entre $10 \mathrm{a}$ 15 toneladas de massa seca. Essa vantagem só é possível devido a possibilidade de mais uma colheita ao ano da gramínea.

O processo de transformação do capim elefante em energia não é muito complicado, após o processo de colheita, estocagem, serão cortados em pequenos pedaços e queimado em uma caldeira, onde serão transformados em energia térmica que aquecerá a água gerando vapor sob pressão, na qual movimentará turbinas acopladas a geradores elétricos. Quando são compactados na forma de briquetes, que são tubos em forma de cilindro compacto, podem ser transformados em carvão vegetal através da pirólise, um dos processos de conversão que será explicado nos próximos tópicos, juntamente com os processos de gaseificação e hidrólise. O poder calorífico com $15 \%$ de umidade chega a $4.200 \mathrm{kcal} / \mathrm{kg}$ devido alto teor de fibras (Mazarella, 2007).

Há poucos empreendimentos registrados no BIG da ANEEL com a cultura de capim elefante para geração de energia elétrica, somente duas em todo território nacional. A maior delas fica localizada no oeste do estado da Bahia, na cidade de São Desidério, a Usina Termelétrica de Sykué, com capacidade instalada de 30 MW.

\subsubsection{Cultura do Coco da Baía}

O coqueiro é uma monocotiledônea e tem sua origem no sudeste asiático, nas ilhas entre os oceanos Pacífico e Indico. O fruto do coqueiro é uma drupa formada por epiderme lisa que envolve o mesocarpo espesso e fibroso. A camada de fibras possui de 3 a $5 \mathrm{~cm}$ de espessura (Ferreira et al., 1998). Santos (2002) citou que as fibras do coco se caracterizam pela dureza e 
durabilidade devido ao alto teor de lignina. A espécie chegou ao Brasil por volta de 1553, pelo estado da Bahia, por esse motivo é chamado de coco-da-baía (Aragão et al., 2010).

O consumo de água de coco tem impulsionado o plantio em todo o país, favorecendo o Brasil a subir no ranking dos maiores produtores de coco do mundo. Segundo os dados da Organização da Nações Unidas para Agricultura e Alimentação (FAO, 2011), o Brasil é o quarto maior produtor de coco verde do mundo. Por ano, o país chega a produzir cerca de 2 bilhões de unidades. Em 1990, ocupava a décima posição entre os produtores, hoje em dia com a quarta posição, só fica atrás de Índia, Filipinas e da Indonésia, maior produtora do mundo. Considerar somente a venda da água de coco, o Brasil é líder mundial e movimenta valores acima dos R \$ 450 milhões com esse negócio segundo a FAO, 2011.

De acordo com o IBGE, 2017 três regiões brasileiras se destacaram na produção de coco entre 2011 e 2017: Nordeste, Sudeste e Norte. Na região Nordeste os estados mais produtores são Bahia, Ceará e Sergipe. Já na região Sudeste, os estados são Espirito Santo, Rio de Janeiro e Minas Gerais e a região Norte, os estados do Pará, Tocantins e Amazonas. Dentre os estados citados acima, a Bahia é o maior produtor desde 2011 segundo o IBGE, 2017. Os municípios baianos maiores produtores de coco são Rodelas, Jandaíra, Esplanada, Acajutiba e Conde.

Segundo Silveira (2008), a casca corresponde a $80 \%$ do coco e com o aumento do consumo da água vendida e consumida, na maioria das vezes, no próprio fruto, acarreta problemas de transporte, armazenamento e acumulo de resíduo sólido urbano. Esses rejeitos geram um volume absurdo de material que atualmente são jogados em lixões a céu aberto, praias, terrenos baldios, possui uma difícil decomposição, podendo levar de oito a quinze anos para se decompor, sem contar que produz gás metano em condições anaeróbicas, gás grande agravador do efeito estufa (SEBRAE, 2015).

Por meio da produção de briquetes, a casca de coco é utilizada para produzir energia, constituindo um uso sustentável de biomassa. Os briquetes podem ser utilizados como fonte energética em diversos processos produtivos dos mais variados tipos de indústrias, além de serem usados para alimentar fornos de pizzarias e padarias. A substituição de lenha por briquetes de coco é uma alternativa sustentável, trazendo ainda uma vantagem que é a combustão mais rápida e estabilidade de temperatura, diferentemente da lenha. O briquete ainda 
detém de um poder calorífico muito alto, com umidade baixa e pouca geração de cinzas (Costa \& Moraes, 2011).

Sendo assim, e em virtude das suas propriedades físicas e químicas, o coco residual pode ser queimando diretamente em fornalhas ou aproveitado como carvão vegetal. Carmo (2013), traz em sua pesquisa, que o poder calorífico superior (PCS) do coco residual é de aproximadamente $5.447,38 \mathrm{kcal} / \mathrm{kg}$ (base seca). A cultivo do coco para fins energético é de caráter exploratório, não há dados suficientes para quantificar as vantagens e desvantagens dessa prática, o que se sabe é que o poder calorífico do coco é extremamente alto em relação a algumas culturas já familiarizadas nos produtores.

\section{Metodologia}

A metodologia aplicada neste trabalho foi composta de pesquisas teóricas sobre a aplicação da biomassa de cana-de-açúcar, coco da baía e capim elefante para fins energéticos. Adicionalmente foram coletados dados da produção das culturas das biomassas estudadas em bases de dados oficiais como a ANEEL - Agência Nacional de Energia Elétrica (https://www.aneel.gov.br/) com informações sobre potência outorgada e plantas industriais destinadas a produção de energia elétrica a partir das culturas vegetais abordadas na pesquisa e o IBGE - Instituto Brasileiro de Geografia e Estatística (https://www.ibge.gov.br/), com levantamento de dados de safras atualizadas de plantio das espécies vegetais selecionadas neste estudo (2017/2018).

Os dados de produção da safra 2017/2018 referentes à cana-de-açúcar e coco da baia foram coletados a partir da PAM - Pesquisa Agrícola Municipal (PAM, 2017) do IBGE. Já os dados de produção sobre a gramínea capim elefante foi obtida do LAPIG - Laboratório de Processamento de Imagens e Geoprocessamento (https://www.lapig.iesa.ufg.br).

Para a estimação do potencial de geração de energia a partir da biomassa proveniente de resíduos agrícolas foram considerados os valores das produções agrícolas de cada estado do Brasil na safra 2017/2018. A partir desses valores calculou-se, os índices citados em literatura, o potencial para cada tipo de resíduo. Esta metodologia de conversão energética foi retirada do Atlas de Bioenergia do Brasil (Coelho et al., 2012). Com base no Atlas, a eficiência de 
conversão (n) adotada para os resíduos foi de 15 a $30 \%$.

O potencial para geração de energia foi calculado multiplicando - se a eficiência da energia produzida $(\mathrm{kW} / \mathrm{t})$ pela quantidade de cana colhida em cada estado do país, dado este, fornecido pelo IBGE (2017/2018); conforme Equação 1.

$$
\mathrm{MW} / \mathrm{ano}=\frac{(\mathrm{Tc} * 30 \mathrm{kWh} / \mathrm{t})}{1,000 * 5,563}
$$

O número 5.563 é referente as horas de operação por ano, considerando que o sistema opere somente durante a safra com os resíduos gerados entre abril e novembro. E o coeficiente 1.000 é um fator de conversão utilizado para cultura da cana-de-açúcar.

A geração da biomassa do capim elefante se dá a partir do cultivo da pastagem, que geralmente é servida para o gado de corte e leiteiro. Com já dito, o capim elefante tem um crescimento rápido, podendo ser feita uma colheita a cada seis meses após o seu plantio, além de permite de duas a quatro colheitas por ano. Nesse estudo, os dados de cultivo no Brasil foram fornecidos pelo LAPIG, 2015 e corresponde a um plantio completo. O aproveitamento da biomassa após processo de secagem e armazenamento deve girar em torno 75 a $85 \%$, pois, de acordo com pesquisas, o poder calorífico pode ser influenciado pela umidade. Mazarella (2007), por exemplo, cita que o poder calorífico com $15 \%$ de umidade chega a $4200 \mathrm{kcal} / \mathrm{kg}$ devido ao alto teor de fibras.

O poder do potencial teórico para geração de energia leva em conta um sistema convencional de turbina a vapor (ciclo Rankine). O rendimento ( $\eta$ ) adotado foi $30 \%$, característicos de equipamentos de médio porte. O PCI do capim elefante adotado foi de 4.100 $\mathrm{kcal} / \mathrm{kg}$ (Marafon et al., 2015) e a conversão de $\mathrm{kcal} / \mathrm{kg}$ para $\mathrm{kWh} / \mathrm{kg}$ foi dada pela divisão por 860. A Equação 2 ilustra o processo.

$$
\mathrm{MW} / \mathrm{ano}=\frac{\left(\mathrm{t}_{\text {capim elefante }} * \mathrm{PCI} \mathrm{kcal} / \mathrm{kg} * \eta\right)}{860 * 8760}
$$

O número 8.760 é referente as horas médias de operação por ano.

Os dados apresentados pelo IBGE do coco da baía são em função de mil frutos, sendo necessário estabelecer um peso médio para cada fruto (aproximadamente 500g) e dividir os valores coletados do IBGE por mil. De acordo com, Torres, Melo e Marcelino (2017), o fruto do coqueiro é constituído por albúmen líquido, amêndoa, endocarpo e casca, sendo que esta 
representa em torno de $57 \%$ do fruto, e é composta por mesocarpo e epicarpo. O PCI da casca do coco (endocarpo), segundo a EMBRAPA, 2016, é de $4.484 \mathrm{kcal} / \mathrm{kg}$. Da mesma forma que os processos das culturas anteriores, a conversão de $\mathrm{kcal} / \mathrm{kg}$ para $\mathrm{kWh} / \mathrm{kg}$ é por $860 . \mathrm{O}$ rendimento para esta cultura será de acordo com equipamentos de pequeno porte, $15 \%$. Sendo assim, tem-se a representação, por meio da Equação 3.

$$
\mathrm{MW} / \mathrm{ano}=\frac{\left.\left(\frac{\text { mil frutos } * 500 \mathrm{~g}}{1000} * 0,57\right) * \mathrm{PCI} \mathrm{kcal} / \mathrm{kg} * 0,15\right)}{860 * 8760}
$$

Diante disso, para construção dos mapas temáticos ilustrando as áreas em que as culturas atualmente estão concentradas, mostrando seus potenciais de aproveitamento para fins energéticos, foi construída uma planilha contendo um banco de dados de cada cultura, com consumo, safra, fornecimento energético. Os mapas temáticos foram criados através do software QGIS Desktop 3.4.2, indicando a área que cada cultura tem mais potencial energético e consumo excedente.

\section{Resultados e Discussão}

As análises dos potenciais de geração de energia elétrica a partir de biomassas estão presentes nos subitens deste tópico, no qual, foi categorizado por culturas, sendo elas, as trabalhadas pela pesquisa: cana-de-açúcar, capim elefante e coco da baía. Em cada cultura foi analisado os respectivos potenciais de geração de energia elétrica.

\subsection{Potencial de Geração de Eletricidade a partir de Cana-de-Açúcar}

O Brasil é o maior produtor e exportador de cana-de-açúcar do mundo, ganhou força após a criação do Proálcool em 1975, isto deixou o Brasil em uma posição favorável ao reaproveitamento dos resíduos da cana-de-açúcar. Com base nos dados da CONAB, a safra de 2017/2018 foi de 635 milhões de tonelada.

Atualmente, segundo a ANEEL, 2019, o Brasil possui uma potência fiscalizada da fonte do bagaço da cana-de-açúcar de $11.352 .247 \mathrm{~kW}$, cerca de 6,63\% da matriz energética do país, o que convertendo de potência (W) para potência elétrica (Wh) e considerando que o tempo de operação seja de acordo com a colheita da safra, que neste caso é de 5563 horas, produziria 
cerca de 63.152,55 GWh de energia elétrica. Com os dados coletado frente ao IBGE, a geração de energia elétrica proveniente da cultura da cana-de-açúcar seria um pouco menor, 53.098,38 GWh. O BEN, 2018 traz que a geração de energia elétrica no Brasil em centrais de serviços público e autoprodutores atingiu $588 \mathrm{TWh}$ em 2017. Sendo assim, tomando como base a hipotética geração de energia elétrica através dos dados coletados do IBGE, a biomassa da canade-açúcar contribuiria com aproximadamente 9\% dessa geração de 588 TWh de energia elétrica.

O mapa (Fig. 2) produzido com os dados coletados do IBGE para a cultura da cana-deaçúcar, mostra que as regiões Sudeste e Centro-oeste são onde estão concentrados os maiores potenciais de geração de energia elétrica para esse tipo de biomassa. No estado de São Paulo o setor gera um potencial de 5.667,75 MW, o equivalente a um potencial elétrico de $31.529,72$ GWh. Logo em seguida vem os estados: Goiás (4.997,12 GWh), Minas Gerais (4.879,25 GWh), Mato Grosso do Sul (3.285,11 GWh) e Paraná (2.850,58 GWh).

De acordo com a União da Indústria de Cana-de-Açúcar (ÚNICA), em 2017, 89,2\% da geração pela fonte bioeletricidade em geral (que inclui as demais biomassas) para a rede esteve concentrada em maior escala nos estados: São Paulo, Mato Grosso do Sul, Minas Gerais e Paraná. Todos eles pertencem a região conhecida como Centro-Sul sucroenergética e o estado que mais gerou bioeletricidade para a rede foi São Paulo, levando cerca de $47 \%$ do volume total do período. Somente a geração sucroenergética paulista para a rede contribuiu com cerca de $20 \%$ ou até mesmo atender a 44\% do consumo total da cidade de São Paulo capital.

Porém, Rodrigues (2010) em sua pesquisa, afirma que a agroindústria da cana-de-açúcar pode causar diversos impactos socioeconômicos e no meio ambiente. Dentre dos principais impactos ambientais negativos estão a redução da biodiversidade, causada pelo desmatamento, expansão da fronteira agrícola, contaminação do solo e da água devido a adubação química, entre outros. Por ser uma monocultura implantada em grandes extensões de terra, no ponto de vista social é apontado como provedor de desigualdades no campo, prejudicando diretamente a agricultura familiar. Além disso, devido a um mercado de terras pouco ordenado jurídico, há muita concentração de propriedade latifundiária. 


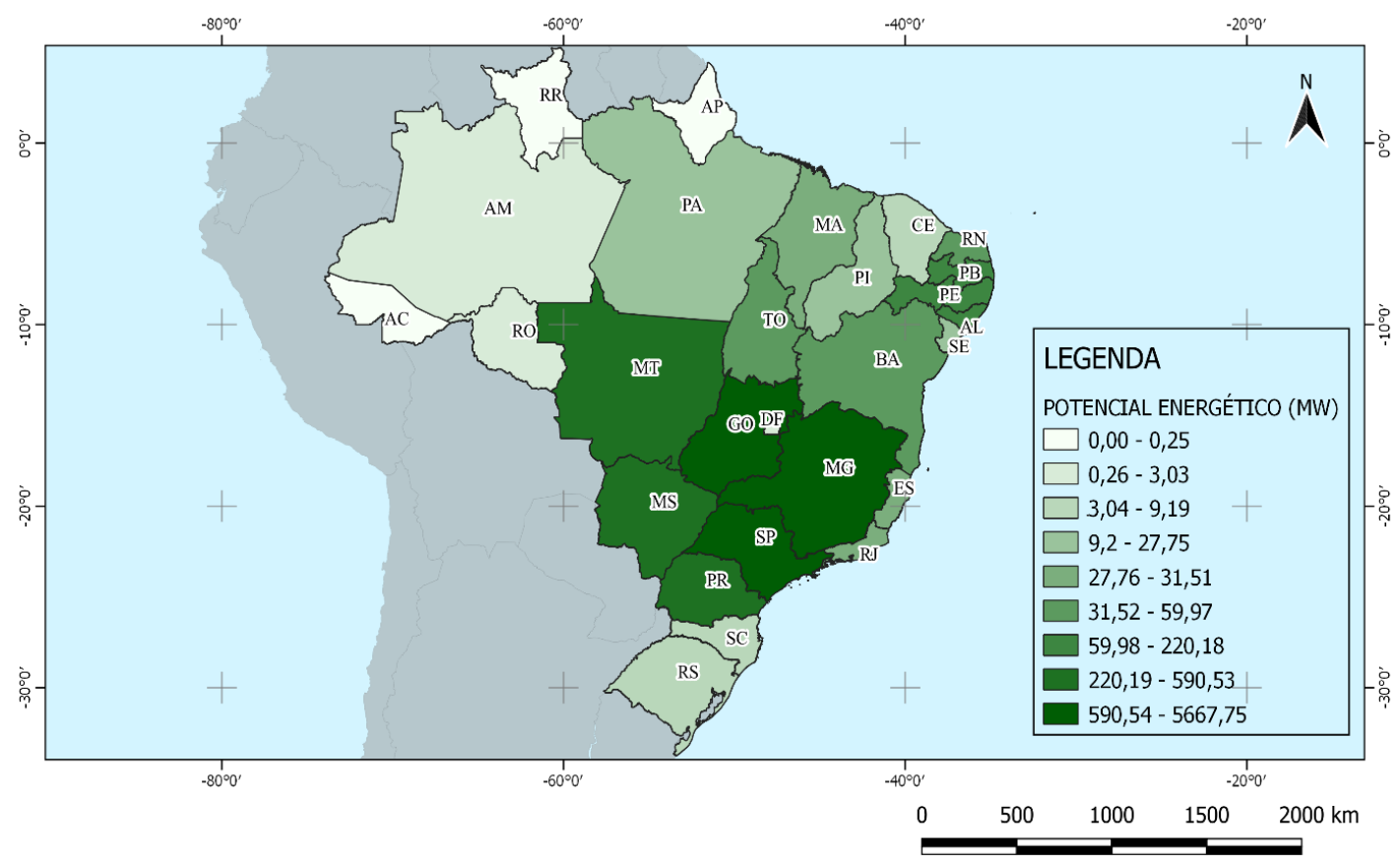

Figura 2. Mapa da estimativa do potencial de geração de energia a partir da biomassa da canade-açúcar cultivada no Brasil

\subsection{Potencial de Geração de Energia Elétrica a partir do Capim Elefante}

A cultura do capim elefante é pouca explorada para fins energéticos, os dados de cultivo são escassos. Segundo o ANEEL, 2019, a fonte de energia com origem da biomassa possui 14.760.537 kW de potência fiscalizada, representando $8,82 \%$ de todo o conjunto da rede da matriz energética principal. A agroindústria é a principal contribuinte entre as demais fontes que compõe o segmento da biomassa, com $77,45 \%$, exatamente $11.247 .231 \mathrm{~kW}$ de potência fiscalizada. O capim elefante faz parte da agroindústria, mas somente representa $0,28 \%$, que representa $31.700 \mathrm{~kW}$ de potência fiscalizada e em termo de produção elétrica, 277,69 GWh.

Uma análise feita no mapa mostrado na Fig. 3, percebeu-se a grande área de abrangência da cultura, quase todos os estados brasileiros possuem uma pequena produção de capim elefante. Com base nos dados coletados do LAPIG, os cinco estados brasileiros com os maiores potenciais energéticos da biomassa do capim elegante são: Minas Gerais, com cerca de 35,72 MW, Mato Grosso (35,20 MW), Bahia (27,17 MW), Mato Grosso do Sul (26,72 MW) e Pará (25,59 MW). A média entre os cinco estados citados é de aproximadamente $30 \mathrm{MW}$, neste caso, 
os valores de potenciais de geração de energia elétrica seria em torno de 262,8 GWh. Este valor contribuiria para somente $1 \%$ da matriz energética, porém, há pontos positivos, a uma vasta abrangência de cultivo, pesquisas estão sendo intensificadas e é uma biomassa com um poder calorifico inferior bastante alto e satisfatório, como já discutido em tópicos anteriores. Vale ressaltar que o tempo de operação de um capim elefante é muito superior ao da biomassa da cana-de-açúcar, geralmente, não há interrupção de uma safra para outra, ou seja, trabalha cerca de 8760 horas.

Segundo a ANEEL, 2019, há somente dois empreendimentos UTE operando para a geração de energia elétrica, legalizada, com a biomassa do tipo capim elefante, uma no Amapá, Flórida Clean Power do Amapá, com uma potência de 1.700 kW e a outra na Bahia. A Sykué, localizada no oeste baiano na cidade de São Desiderio, possui capacidade instalada de $30 \mathrm{MW}$, o equivalente aos mesmos 262,8 GWh resultante da média dos cinco maiores produtores de capim elefante do país. Caso os demais estados aproveitassem os seus potencias assim como a Bahia, teria uma contribuição de cerca de $1.079,5 \mathrm{GWh}$, um aumento de $388 \%$ em relação aos dados da ANEEL de potência fiscalizada do capim elefante.

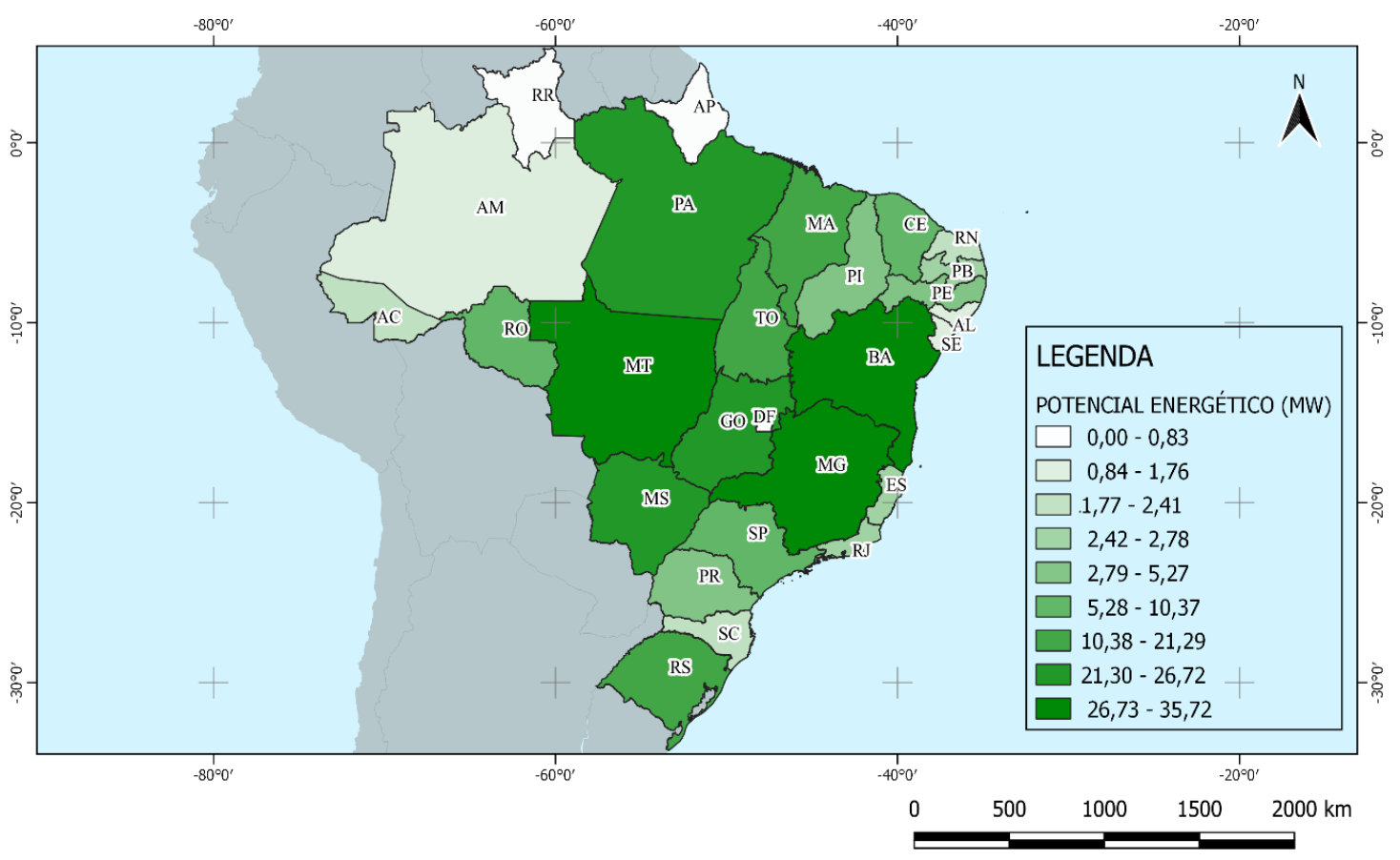

Figura 3. Mapa da estimativa do potencial de geração de energia a partir da biomassa do capim elefante cultivado no Brasil 


\subsection{Potencial de Geração de Eletricidade a partir de Coco-da-Baía}

As três regiões brasileiras que se destacaram a produção de coco da baía entre 2011 e 2017 , segundo o IBGE, 2017, foram: Nordeste, Sudeste e Norte. Na região Nordeste os maiores estados produtores são Bahia, Ceará e Sergipe. Já na região Sudeste, os estados são Espirito Santo, Rio de Janeiro e Minas Gerais e na região Norte são os estados do Pará, Tocantins e Amazonas líderes em produção do coco da baía. Dentre eles, a Bahia é o maior produtor do Brasil desde 2011 de acordo com IBGE, 2017. Os municípios baianos maiores produtores de coco são Rodelas, Jandaíra, Esplanada, Acajutiba e Conde.

A Figura 4 representa o mapa criado através dos dados coletados PAM (IBGE, 2017). Com ele é possível identificar exatamente os estados com maiores e menores potenciais energético através da biomassa proveniente do coco da baía. Segundo o PAM, o Brasil tem um potencial energético de aproximadamente 30,25 MW. A Bahia é responsável por 22\% dessa produção, cerca de 6,80 MW. Seguidamente vem os estados do Sergipe e Ceará com 4,54 MW (14\%) e 3,62 (11\%), respectivamente. Em termos de potência elétrica, o Brasil teria um acréscimo de $265 \mathrm{GWh}$ na sua capacidade de energia interna.

O estado da Bahia seria capaz de fornecer 59,57 GWh para seu consumo interno, aliviando o alto consumo das hidrelétricas, na qual diversas vezes no Nordeste, há crises hídricas devido à escassez de chuvas. De acordo com o Anuário Estatístico de Energia Elétrica (2018), a geração elétrica por fonte no Brasil em 2017 foi de 587.962 GWh, no qual a biomassa contribui com 8,4 \% desse total, cerca de $49.385 \mathrm{GWh}$, número que facilmente seria multiplicado caso houvesse um melhor aproveitamento dos potenciais energéticos das energias renováveis. 


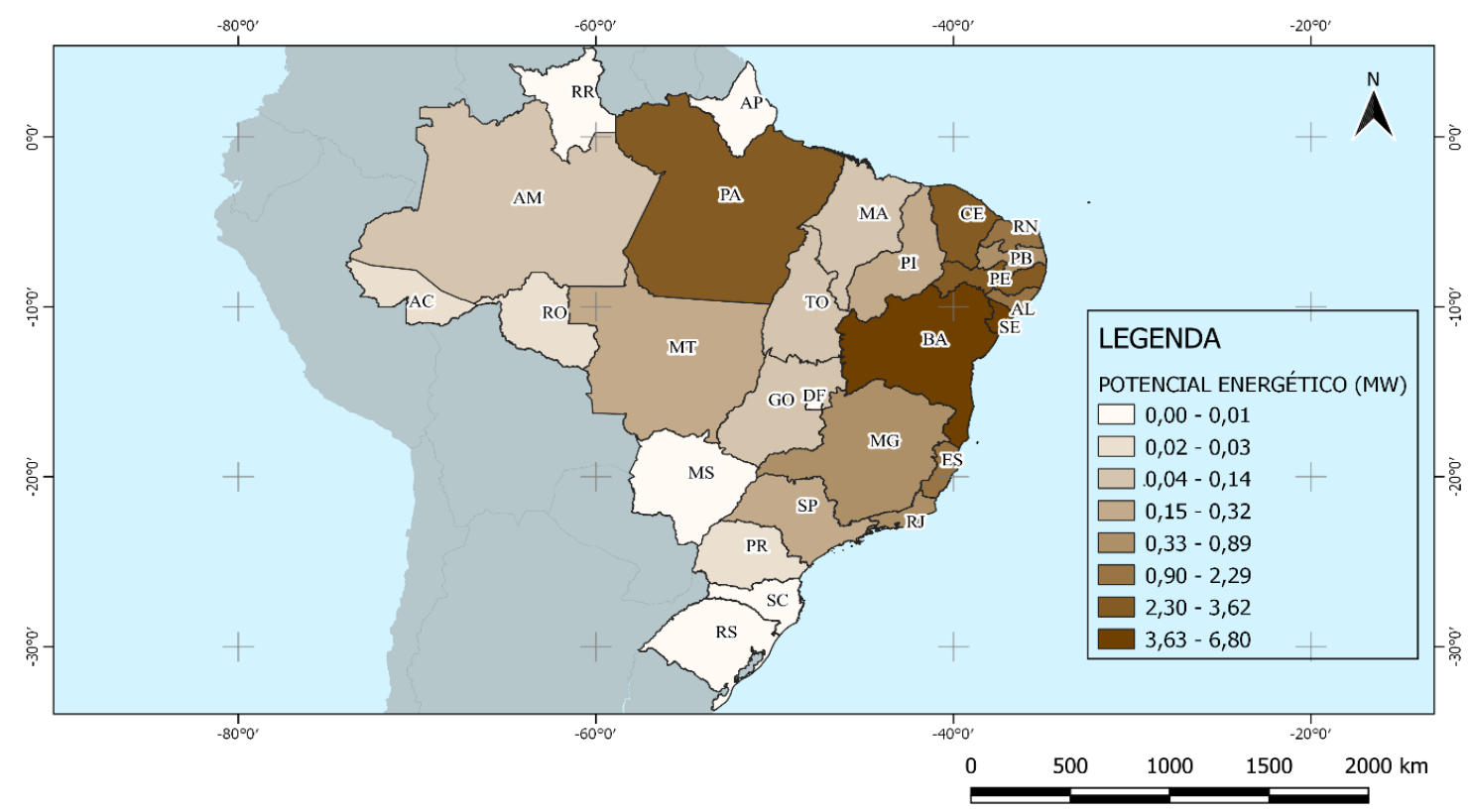

Figura 4. Mapa da estimativa do potencial de geração de energia a partir da biomassa do coco da baía cultivado no Brasil

O Anuário Estatístico de Energia Elétrica (2018) informa que o Nordeste até o ano base de 2017, possuía uma capacidade instalada de 32.505 MW, cerca de $20,7 \%$ de toda capacidade do Brasil, superado apenas pela região Sudeste que possuía uma capacidade 45.512 MW (28,8\%). Em geração elétrica, o Sudeste fornece 31,2 \% da malha energética do Brasil, cerca de 183.453 GWh, logo em seguida vem a região do Sul do país, com 148.196 GWh (25,2\%). A Região Nordeste possui um índice de geração de 96.028 GWh (16,3 \%), o Norte com 94.762 GWh $(16,1 \%)$ e por último o Centro - Oeste com 65.523 GWh $(11,1 \%)$. Analisando tais números e relacionando com os potenciais demonstrados pelos mapas e o quanto de energia elétrica seria produzido, percebe - se o quanto de desperdício potencial há no Brasil, que já é pioneira em energia renovável.

Recentemente, o Comitê de Monitoramento do Setor Elétrico (CMSE) optou em elevar o número de termelétricas acionadas no país como medida para preservar os reservatórios das hidrelétricas que estão com nível de armazenamento baixo devido à falta de chuva. Estima - se um gasto por Megawatts-hora $(\mathrm{MWh})$ de até $\mathrm{R} \$ 588,75$, valor que está diretamente ligado a conta de luz do consumidor.

\section{Conclusões}


Este trabalho teve como objetivo mapear e analisar o potencial de geração de energia elétrica e o potencial excedente, caso houvesse, a partir das culturas bioenergéticas da cana-deaçúcar, capim elefante e coco da baía. A utilização de energias renováveis reduz a dependência energética que ainda existe no Brasil, ajuda a garantir uma melhor vida útil dos reservatórios das usinas hidrelétricas, aumenta a diversificação da matriz energética, garantindo o suprimento de energia, sem contar os impactos positivos que geram no ecossistema.

Apesar da biomassa ter sido a primeira fonte energética utilizada pela humanidade, a sua aplicação é muito pequena ainda. No Brasil é de aproximadamente 8\% da matriz energética, mas em constante desenvolvimento. A biomassa ainda é atrelada a fontes difundidas como o bagaço de cana e o licor negro, o qual, não foi abordado na pesquisa. A regulamentação permite a inserção de novas biomassas na matriz energética, por isso a abordagem em duas culturas inovadoras, capim elefante e coco da baía, a fim de ampliar o leque de opções disponíveis no Brasil, uma país rico territorialmente e com climas favoráveis a práticas agroindustriais.

As analises por exemplo no estado da Bahia são animadoras, pois, com os resultados aqui analisados da cultura do coco da baía, poderia disponibilizar cerca de 59,52 GWh ao estado. Isso desconsiderando a Termelétrica de Sykué que utiliza o capim elefante como matéria prima. É importante frisar os principais benefícios do uso de biomassa como fonte de geração de energia elétrica: ser uma fonte renovável com menor emissão de gases, geração de empregos locais, seria de extrema importância um incentivo do governo estadual e federal para que isso ocorra. Em síntese, é preciso que haja um ponto de vista socioambiental.

\section{Referências}

ANEEL - Agência Nacional De Energia Elétrica (2008). Atlas de energia elétrica do Brasil. Disponível em: <http://www.aneel.gov.br/documents/656835/14876406/2008_AtlasEnergiaEletricaBrasil3ed/ 297ceb2e-16b7-514d-5f19-16cef60679fb>. Acessado em 02 de dezembro de 2018.

ANEEL - Agência Nacional de Energia Elétrica (2019). Banco De Informação De Geração Aneel, http://www2.aneel.gov.br/aplicacoes/capacidadebrasil/capacidadebrasil.cfm. Acessado em 12 de janeiro de 2019.

Aragão, W. M.; Tupinambá, E. A.; Ângelo, P. C. da S.; Ribeiro, F. E. (2010). Seleção de 
cultivares de coqueiro para diferentes ecossistemas do Brasil In: Queiroz M.A (Org.). Recursos energéticos e melhoramento de plantas para o Nordeste brasileiro. Ed. Embrapa, 2010, p. 125 .

Barum, A. O. (1999). Aspectos socioeconômicos da utilização intensiva de biomassa na geração de energia. Sociedade em Debate, Pelotas, 5(3): 91-100.

BEN - Balanço Energético Nacional - Ano base 2014 (2015). Relatório Síntese. Brasil. Empresa de Pesquisa Energética. Rio de Janeiro, EPE, pp. 62, 2015.

BEN - Balanço Energético Nacional - Ano base 2017 (2018). Relatório Síntese. Brasil. Empresa de Pesquisa Energética. Rio de Janeiro, EPE, pp. 77, 2018.

Cardoso, B. M. (2012). Uso da Biomassa como Alternativa Energética. Monografia, Curso de Graduação em Energia Elétrica - Escola politécnica. UFRJ, Rio de Janeiro, Brasil. 112 p. 2012. Disponível em: https://pantheon.ufrj.br/handle/11422/8982. Acessado em 14 de março de 2019.

Cardoso, T. F. (2011). Cogeração de Energia através do Bagaço de Cana-de-Açúcar: Revisão de Literatura. Dissertação de Mestrado, Programa de pós-Graduação em Gestão de Produção Sucroenergética. UFSCAR, São Paulo, Brasil. 22 p. Disponível em: https://www.mta.ufscar.br/arquivos/publicacoes/sertaozinho-ii/monografia-tiago-fioricardoso.pdf. Acessado em: 28 de janeiro de 2019.

Carmo, V. B. (2013). Avaliação da eficiência energética renovável de biomassas alternativas para geração de eletricidade. Tese de Doutorado, Programa de Pós-Graduação em Engenharia Química. Unicamp, São Paulo, Brasil. 170 p. Disponível em: http://repositorio.unicamp.br/jspui/handle/REPOSIP/266061. Acessado em: 03 de fevereiro de 2019.

Carmo, V. B. \& Hasan, N. M. (2015). Mapeamento dos recursos naturais e potencialidades para a economia verde no Brasil. In: XV Safety, Health and Environment World Congress, 22, 2015, Cidade do Porto - Portugal.

Coelho, S. T.; Monteiro, M. B.; Karniol, M. R. (2012). Atlas da Bioenergia do Brasil - Projeto Fortalecimento Institucional CENBIO - São Paulo.

CONAB - Companhia Nacional De Abastecimento (2018). Acompanhamento da Safra Brasileira - Cana de Açúcar - Safra 2017/2018. Disponível em: https://www.conab.gov.br/ultimas-noticias/2327-cana-de-acucar-tem-queda-de-3-6-e-fechasafra-2017-18-em-633-26-milhoes-de-t. Acessado em 14 de julho de 2019.

Costa, G. P. \& Moraes, J. T. A. (2011). Fabricação de Briquetes como Alternativa para Destinação Adequada dos Resíduos de Madeira na Indústria Moveleira no Espírito Santo. 5, 2011, Vitória. Disponível em: http://faesa.br/SEA/. Acessado em 13 de janeiro de 2019.

Dias, E. O. et al. (2017). Biomassa: oportunidades de geração de eletricidade no estado da Bahia. 
Bahia Análise \& Dados, V. 27 (1), p. 312-335.

EMBRAPA - Empresa Brasileira de Pesquisa Agropecuária (2015). Agência Embrapa de Informação Tecnológica - Estatística da Produção. Disponível em: https://www.agencia.cnptia.embrapa.br/gestor/coco/arvore/CONT000fo7hz6ox02wyiv806561 0d6ky3ary.html. Acesso em 14 de janeiro de 2019.

FAO - Organização das Nações Unidas para Alimentação e Agricultura (2011). World Production. Disponível em: www.faostat.org. Acessado em 13 de janeiro de 2019.

Ferreira, J. M. S.; Warwick, D. R. N.; Siqueira, L. A. (1998). A cultura do coqueiro no Brasil. 2. ed. Brasília, EMBRAPA, 292 p.

Hugot, E. (1986). Handbook of Cane Sugar Engineering. 3. ed. Amsterdam, Elsevier Science Publisher, $1186 \mathrm{p}$.

IBGE - Instituto Brasileiro de Geografia e Estatística (2017). Produção Agrícola Municipal do ano de 2017. Disponível em: http:www.sidra.ibge.gov.br/bda/pesquisa. Acessado em 13 de fevereiro de 2019.

IEA - International Energy Agency (2007). Energy Effciency Indicators for Public Electricity Production from Fossil Fuels. Information Paper in support to the G8 Plan of Action. Disponível em: https://www.iea.org/papers/2008/En_Efficiency_Indicators.pdf. Acessado em 21 de janeiro de 2019.

IEA - International Energy Agency (2012). Medium-term renewable energy market report 2014. Disponível em: https://www.iea.org/reports/medium-term-renewable-energy-market-report2014. Acessado em 25 de março de 2019.

LAPIG - Laboratório de Processamento de Imagens e Geoprocessamento (2015). Atlas das pastagens brasileiras. Disponível em: https://www.lapig.iesa.ufg.br/lapig/index.php/produtos/atlas-digital-das-pastagens-brasileiras. Acessado em 21 de janeiro de 2019.

Marafon, A. C. et al. (2016). Poder calorífico do capim elefante para geração de energia térmica. Boletim de desenvolvimento e pesquisa da Embrapa. Disponível em: https://www.embrapa.br/busca-de-publicacoes/-/publicacao/1060103/poder-calorifico-docapim-elefante-para-a-geracao-de-energia-termica. Acessado em 30 de janeiro de 2019.

Marcelino, M. M.; Melo, S. A. B. V.; Torres, E. A. (2017). Caracterização da biomassa da casca de coco para obtenção de energia. Bahia análise \& Dados, v. 27, n. 1, p. 336-355.

MME - Ministério de Minas e Energia (2018). Boletim de Monitoramento do Sistema Elétrico - Junho 2018. Disponível em: http://www.mme.gov.br/web/guest/pagina-inicial/outrasnoticas/-/asset_publisher/32hLrOzMKwWb/content/energia-limpa-brasil-registra-88-defontes-renovaveis-na-producao-de-energia-em-junho. Acessado em 14 de aneiro de 2019. 
Rodrigues, L. D. (2010). A cana-de-açúcar como matéria-prima para a produção de biocombustíveis: impactos ambientais e o zoneamento agroecológico como ferramenta para mitigação. Curso de Especialização de Análise Ambiental. UFJF, Juiz de Fora, Brasil 64 p. Disponível emarquivo http://atividaderural.com.br/artigos/5601927a79cad.pdf. Acessado em: 24 de janeiro de 2019.

Santos, F.; Borém, A.; Caldas, C. (2012). Cana-de-açúcar: bioenergia, açúcar e etanol: tecnologias e perspectivas. 2. ed. rev. e ampl., Viçosa, MG, Os Editores, 637 p.

Santos, J. A. F. de A. \& Torres, E. A. (2017). Projeções de aumento da geração elétrica via bioeletricidade no estado da Bahia. In: Encuentro Regional Iberoamericano, 17, Gicrê.

Santos, M. S. Propriedades térmicas e mecânicas de materiais reciclados a base de PET pós consumo e cargas de coco. (2002). Dissertação de Mestrado, Programa de Pós-Graduação em Ciência e Tecnologia de polímeros. UFRJ, Rio de Janeiro, Brasil 85p. Disponível em: http://hdl.handle.net/11422/1613. Acessado em 22 de janeiro de 2019.

SEBRAE - Serviço Brasileiro de Apoio às Micro e Pequenas Empresas (2015). Água de coco e suas propriedades isotônicas impulsionam a produção de coco verde no país, inclusive no interior de vários estados. Disponível em: http.www.sebrae.com.brsitesPortalSebraeartigosOcultivo-e-omercado-do-coco-verde. Acessado em 13 de janeiro de 2019.

Tolmasquim, M. T. (2015). Novo modelo do setor elétrico brasileiro. $2^{\mathrm{a}}$ ed. Rio de Janeiro: Synergia, EPE - Brasília, 310p.

Financiamento: Esta pesquisa não recebeu nenhum financiamento.

Conflitos de interesse: Os autores declaram não haver conflitos de interesse.

Aprovação do comitê de ética: Não aplicável.

Disponibilidade dos dados da pesquisa: Todos os dados utilizados e analisados neste estudo são de acesso aberto. Disponíveis nos sítios do IBGE (http:www.sidra.ibge.gov.br/bda/pesquisa) e LAPIG (https://www.lapig.iesa.ufg.br/lapig/index.php/produtos/atlas-digital-das-pastagensbrasileiras).

\section{Contribuição dos autores:}

Idealização, investigação e execução da pesquisa: ANDRADE, D. A. S. de; Condução, revisão metodológica, correção e revisão total do manuscrito: MARTINS, L. O. S. 